East African Medical Journal Vol. 87 February 2010

OCCUPATIONAL NOISE-INDUCED HEARING LOSS AMONG WORKERS AT JOMO KENYATTAINTERNATIONAL AIRPORT, NAIROBI

J. O. Anino, MBChB, MPH, A. Afullo, PhD, Department of Public Health, Kenyatta University, P.O Box 43844, Nairobi, Kenya and F. Otieno, MBChB, MMed, Department of Clinical Medicine and Therapeutics, College of Health Sciences, University of Nairobi, P. O. Box 19676-00202, Nairobi, Kenya

Request for reprints to: Dr. J.O. Anino, P.O. Box 3405 - 00100, Nairobi, Kenya

\title{
OCCUPATIONAL NOISE-INDUCED HEARING LOSS AMONG WORKERS AT JOMO KENYATTA INTERNATIONAL AIRPORT, NAIROBI
}

\author{
J. O. ANINO, A. AFULLO, F. OTIENO
}

\begin{abstract}
Background: Occupational noise induced hearing loss (NIHL) occurs among workers exposed to excessive amounts of noise for long durations. The average level of noise in some locations at Jomo Kenyatta International Airport (JKIA) was above the safe limit of $85 \mathrm{~dB}$ hence workers were thought to be at risk.

Objective: To determine the occurrence and socio demographic attributes for NIHL at JKIA.

Design: Cross sectional descriptive study.

Setting: Jomo Kenyatta International Airport, Nairobi, Kenya.

Results: Mean age of respondents was 37 years with range 22 to 62, SD 8.98. Mean duration of exposure to noise was 10.7 years with range 1 to 40, SD 8.15. Prevalence of NIHL was $15.3 \%$, with ground crew at $14.8 \%$ and air crew $16.1 \%$. Ground crew had significantly poorer mean hearing threshold level at 3,4 and $6 \mathrm{kHz}$ than air crew $(p=0.015)$. Male workers were affected more than female counterparts with a male to female ratio of 4:3. $97 \%$ of those affected were non-managers, $3 \%$ managers while $68 \%$ of those affected resided in Embakasi Division close to the airport. Hearing threshold level at $4 \mathrm{kHz}$ deteriorated with increasing age whereby those aged 50 years and above had a 13.7 times higher relative risk than those aged 20 to 29 years. Duration of exposure more than 10 years also had significantly higher risk $(p<0.01)$ for hearing loss at $4 \mathrm{kHz}$. Conclusion: Occupational noise induced hearing loss occurs at JKIA and that ground crew and older workers are more vulnerable. We recommend that prevention programmes be put in place.
\end{abstract}

\section{INTRODUCTION}

Noise induced hearing loss (NHIL) refers to the characteristichearing loss which results from exposure to noise for excessive duration and intensity (1). Occupational NIHLis the cumulative hearing loss that develops due to exposure to excessive noise levels as a consequence of one's work environment. Excessive noise damages the outer hair cells of the organ of Corti in theinner ear. Thisloss corresponds to the audiometric finding of a sensorineural hearing loss that does not recover (2). Jomo Kenyatta International Airport (JKIA) has been documented to have potentially hazardous noise from aircrafts and motorized ground equipment(3). Theenvironmental auditcommissioned by Kenya Airports Authority (KAA) and National Environmental Management Authority (NEMA) in year 2006 found noise pollution from aircraft engines, ground runs, ground transport, construction works and ground support equipments (4). Muriuki found that noise pollution in the airport offices next to the apron was inevitable during aircraft landing and taking off (5). The recorded average level of noise at JKIA was above the WHO recognised safe limit of $85 \mathrm{~dB}$, and also above the legal acceptable limit of 90dB in Kenya $(5,6)$. Workers at JKIA were considered to be at risk of suffering preventable occupational noise induced hearing loss. The study objective was to determine the prevalence of occupational noise-induced hearing loss among workers at Jomo Kenyatta International Airport Nairobi and describe their socio demographic attributes.

\section{MATERIALS AND METHODS}

A cross-sectional descriptive survey design was used.

Location: Jomo Kenyatta International Airport, Nairobi is situated at Embakasi Division 18 kilometres to the East of Nairobi. It was chosen because it is the 
biggest Airport in East and Central Africa, and is the focal point for major aviation activity in the region. It handles about 4.5 million passengers a year. JKIA is served by 49 scheduled airlines. Aircrafts frequently operated are of several types and sizes ranging from light Cesna, medium Ambraer to large wide body Boeing 777, Airbus A300 and others. JKIA has direct flight connections to Europe, the Middle East, Far East and the African Continent. Nairobi is about $1680 \mathrm{~m}$ above sea level on Longitude 3650' east and Latitude $1^{10} 18^{\prime}$ south of Equator.

Study subjects: The target population to which the study findings are projected is the community of workers exposed to noise in aviation industry. The dependent variable was the hearing threshold level of an employee exposed to workplace noise. The independent variables included nature of work, duration of exposure and socio demographic attributes.

Sampling: There were about ten thousand employees working for 262 companies at JKIA. Stratified random sampling was used to select a representative sample of respondents. Employees were stratified into air crew and ground crew. Aircrew included cockpit and cabin staff of commercial airlines. Ground crew included engineers, technicians, flight dispatchers, firemen, customer service agents and security agents. Volunteers in targeted noisy jobs were approached individually. The sample size was determined using the formula by Fisher et al (9). A minimum of 246 workers were required to be recruited into the study, the actual number recruited were 249. Determination of size of each stratum was by proportionate distribution as described by Nassiuma (10). The minimum number of ground crews that were required was 160 and air crew 86 .

Data collection and research instruments: The research instruments used were a self administered questionnaire, a form for recording observations made unobtrusively and a clinical data sheet for clinical examination findings. The medical equipments included the audiometer, otoscope and tuning fork. The questionnaire was administered to all participating workers and data collected on socio demographic attributes. There were clinical examinations involving otoscopy and audiometry on selected subjects. Weber and Rhine tests were done using standard $256 \mathrm{~Hz}$ tuning fork to differentiate conduction and sensorineural hearing loss as described by Rabinowitz (7). Otoscopy was done using hand held Riester 2050 otoscope with light to examine outer ear and tympanic membrane. Audiometric measurements were conducted in a sound-treated room by the researcher. The standard Cahart and Jerger protocol of measuring the intensity (decibels) at which a pure tone can be heard at a specific frequency was used. The threshold value was the lowest signal intensity that the subject could detect at least $50 \%$ of the time, with a minimum of three trials (8). A Grason-Stadler audiometer (Model GSI 66) calibrated with standard specifications was used as per the manufacturer's manual. Air conduction thresholds were measured for each ear at $0.125,0.25,0.5,0.75,1,2,3,4,6$, and 8 $\mathrm{kHz}$, with testing repeated at $1 \mathrm{kHz}$. The $1 \mathrm{kHz}$ first test was the value used for the analysis. Threshold values were recorded in $5 \mathrm{~dB}$ increments. NIHL has a distinct audiometric pattern (noise notch), with 3, 4 , or $6 \mathrm{kHz}$ typically affected at the onset of NIHL. A diagnosis of NIHL was made when the audiogram met a 3-point criterion for at least one ear. First the threshold value at $0.125,0.25,0.5,0.75$ and $1 \mathrm{kHz}$ had to be $15 \mathrm{~dB}$ hearing threshold level or better. Second, the poorer threshold value at 3,4 , or $6 \mathrm{kHz}$ had to be at least $15 \mathrm{~dB}$ worse than the poorer value for $0.125,0.25$, $0.5,0.75$ and $1 \mathrm{kHz}$. Third, the value at $8 \mathrm{kHz}$ had to be at least $10 \mathrm{~dB}$ better than the poorest threshold value for 3,4 , or $6 \mathrm{kHz}$ (11) (Figure 1). NIHL was categorised into mild, moderate, moderately severe, severe and profound. The categories were defined according to the hearing threshold levels, whereby less than $20 \mathrm{~dB}$ was normal, 20-40dB mild, 40-55dB moderate, 55$70 \mathrm{~dB}$ moderately severe, $70-90 \mathrm{~dB}$ severe and more than $90 \mathrm{~dB}$ was profound hearing loss (12). The study was limited to workers at JKIA, who were exposed to excessive noise for at least one year. Employees known to have deafness of a different cause were excluded. Those only fleetingly exposed (e.g. stationed at areas in JKIA with no significant noise hazard) were excluded. Audiometry could not discriminate speech and subtle hearing difficulties attributable to noise pollution. It also did not rule out co-morbidities, hence anybody who had an audiogram fitting the criteria and was working at JKIA was assumed to have NIHL. Validity was ensured by consistent uniform administration of questionnaire which was filled in by researcher during the interview. Validity of audiometric data was subject to instrument limitations of hearing thresholds that could be reliably measured, which at $4 \mathrm{kHz}$ is about $10 \mathrm{~dB}$. In making measurements and documenting results, standard practices for instrument calibration, measurement techniques, sampling strategy, methodology and data recording were consistently followed. The correlation of the threshold value for each worker for the $1-\mathrm{kHz}$ first test with the retest was $0.89(\mathrm{p}<0.001)$ and $0.81(\mathrm{p}<0.001)$ for the left and right ear respectively. Reliability was ensured by the fact that only one suitably qualified person conducted the audiometric tests eliminating inter-observer error.

Ethical consideration: The study was approved by the ethical committee of Kenyatta University. Participation was voluntary with informed consent from individual employees. No incentives were 
provided except a promise of report of findings and recommendations. Data collected were handled with utmostconfidentiality. Referrals for medical care were arranged through the appropriate airport clinics.

Data analysis: Subjects were described by reported socio demographic characteristics, number of affected ears, and involved frequencies. Data was aggregated for analysis and described by sample size, frequency, mean, median, variance and standard deviation. Comparison of means was done using the t-test. Analysis of contingency tables was done using Chi square test. All prevalence estimates and 95\% confidence intervals were derived using SPSS statistical package.

\section{RESULTS}

Table 1 shows the socio demographic characteristics of the respondents. Two hundred and forty nine respondents were interviewed with 162 being ground crew and 87 air crew. The female workers were outnumbered by their male counterparts at 74 $(30 \%)$ and $175(70 \%)$ respectively. The age range for respondents was 22 to 62 years with mean 37 years and SD of 8.98. The age and sex distribution showed that most of the workers $(86 \%)$ were young peoplebetween the ages of 20 to 49 years. The greatest proportion of the respondents (34\%) was in the 30-39 years age group followed by $40-49$ years (30\%) and $20-29$ years $(22 \%)$. Less than $10 \%$ were aged 50 years and above. Most of the ground crews were aged 30-49 years while the air crews were evenly distributed between 20-49 years. Mean age for the ground crew (38 years) was higher than air crew (36 years). In terms of places of residence, $92 \%$ hailed from residences in Nairobi and $8 \%$ outside Nairobi. Embakasi Division had thehighest proportion of respondents $64 \%$. As for education, 95\% attained a minimum of secondary school education and above, with $43 \%$ reporting secondary schooling as their highest. Forty one per cent had mid-level college training and 10\% had university education. About 5\% had postgraduateeducation. This was notunexpected since formal education is a required competency for nearly all the jobs at this workplace. In relation to income levels, $68 \%$ earned salaries of between Kenya Shillings 5001 to 50,000 (US \$ 64-641) and 29\% earned more than 50,000 (US \$ 641). One hundred and sixty two $(65 \%)$ of the respondents were ground crew and $87(35 \%)$ air crew.

The duration of exposure ranged from 1 to 40 years, mean 10.7 with SD 8.15 and median nine years and interquartile range of 10 . Seventy six per cent $(189 / 249)$ of the workers recruited were members of trade unions, and the rest were not. The air crews were mainly cabin crew $(86 / 87)$ with only one being a flight deck crew. Thirty four per cent $(55 / 162)$ of the ground crews were cabin groomers (aircraft cleaning services). Twenty four per cent were loading agents, $9 \%$ technicians or engineers. Others were drivers $(24 \%)$, passenger handlers $(5 \%)$ and contractors $(2 \%)$. The location of work for the ground crew was mainly airside passenger ramp (70\%) with about $18 \%$ working at the aprons, $5 \%$ in the hangars and $2 \%$ in the workshops.

The number of respondents with NIHL was determined at 38 out of 249 , giving a prevalence rate of $15.3 \%$. Figure 1 shows an audiogram of one of the respondents with NIHL. The mean age of the NIHL group was 35.2 years, SD 7.43, mean duration of exposure 9.6 years, SD 7.39. Ninety seven per cent $(37 / 38)$ of them were non-managers or junior staff and one was a manager. Sixty three per cent $(24 / 38)$ were ground crew and $37 \%$ air crew. The severity of hearing loss among the affected workers was in the category of mild hearing loss (66\%) and moderate hearing loss (19\%). Only about 3\% had moderately severe hearing loss, 5\% had severe and $8 \%$ had profound NIHL. The prevalence of NIHL among ground crew was $14.8 \%$ and among air crew was $16.1 \%$. The prevalence among the ground crew was highest for engineers at $20 \%$, followed by cargo and freight handlers at $18.4 \%$ and equipment operators at $18.4 \%$. The prevalence for NIHL among male workers was $16.6 \%$ and among female workers was $12.2 \%$ with a male to female ratio of 4:3 (Table 2).

\section{Table 1}

Summary of the distribution of respondents by socio demographic characteristics

Distribution of respondents by age and type of work

\begin{tabular}{lcccc} 
Age (years) & Ground crew & Air crew & Total & $(\%)$ \\
\hline $20-29$ & 29 & 25 & 54 & 22 \\
$30-39$ & 60 & 25 & 85 & 34 \\
$40-49$ & 50 & 25 & 75 & 30 \\
$>50$ & 16 & 8 & 24 & 10 \\
No response & 7 & 4 & 11 & 4 \\
Total & 162 & 87 & 249 & 100
\end{tabular}

Distribution by place of residence

$\begin{array}{lcc}\text { Embakasi } & 158 & 63.5 \\ \text { Outside Nairobi } & 21 & 8.4 \\ \text { Makadara } & 17 & 6.8 \\ \text { Kibera } & 15 & 6 \\ \text { Kasarani } & 9 & 3.6 \\ \text { Pumwani } & 8 & 3.2 \\ \text { Central } & 7 & 2.8 \\ \text { Dagoretti } & 6 & 2.4 \\ \text { Westlands } & 6 & 2.4 \\ \text { No response } & 2 & 0.8 \\ \text { Total } & 249 & 100\end{array}$


Distribution by level of education

No formal education

Primary

Secondary

College/diploma / certificate

University

Postgraduate

No response

Total

Distribution by level of income (Kenya Shillings)

Salary band

$0-5,000^{*}$

$5,001-50,000$ *

$50,001^{*}$ and above

No response

Total

$\begin{array}{cc}1 & 0.4 \\ 174 & 69.9 \\ 66 & 26.5 \\ 8 & 3.2 \\ 249 & 100\end{array}$

Distribution of respondents by duration of noise exposure (years)

\begin{tabular}{lcc}
$0-4$ & 56 & 22.5 \\
$5-9$ & 80 & 32.1 \\
$10-14$ & 29 & 11.6 \\
$15-19$ & 37 & 14.9 \\
$20+$ & 33 & 13.3 \\
No response & 14 & 5.6 \\
\hline Total & 249 & 100 \\
\hline
\end{tabular}

1 US dollar $=78$ Kenya Shillings
Table 2

Prevalence of NIHL for some categories of workers

Prevalence of NIHL by nature of work for ground crew

\section{Respondents (\%) NIHL Prevalence}

\begin{tabular}{lcccc}
\hline $\begin{array}{l}\text { Engineers } \\
\text { Cargo/freight }\end{array}$ & 15 & 9 & 3 & 20.0 \\
$\begin{array}{l}\text { handling } \\
\text { hand }\end{array}$ & 38 & 23 & 7 & 18.4 \\
$\begin{array}{l}\text { Drivers } \\
\text { Passenger }\end{array}$ & 38 & 23 & 7 & 18.4 \\
handling & 8 & 5 & 1 & 12.5 \\
Cabin & & & & \\
grooming & 55 & 34 & 6 & 10.9 \\
Contractors & 4 & 3 & 0 & 0 \\
Other & 1 & 1 & 0 & 0 \\
No response & 3 & 2 & 0 & 0 \\
\hline Total & 162 & 100 & 24 & 14.8 \\
\hline
\end{tabular}

Prevalence of NIHL by nature of work for air crew

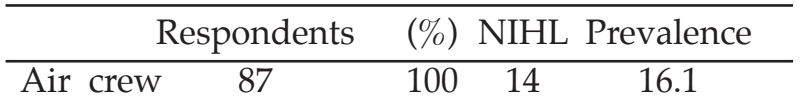

Prevalence by sex

\begin{tabular}{lcccc} 
Male & 175 & 70 & 29 & 16.6 \\
Female & 74 & 30 & 9 & 12.2 \\
\hline Total & 249 & 100 & 38 & 15.3
\end{tabular}

Figure 1

Audiogram for one respondent

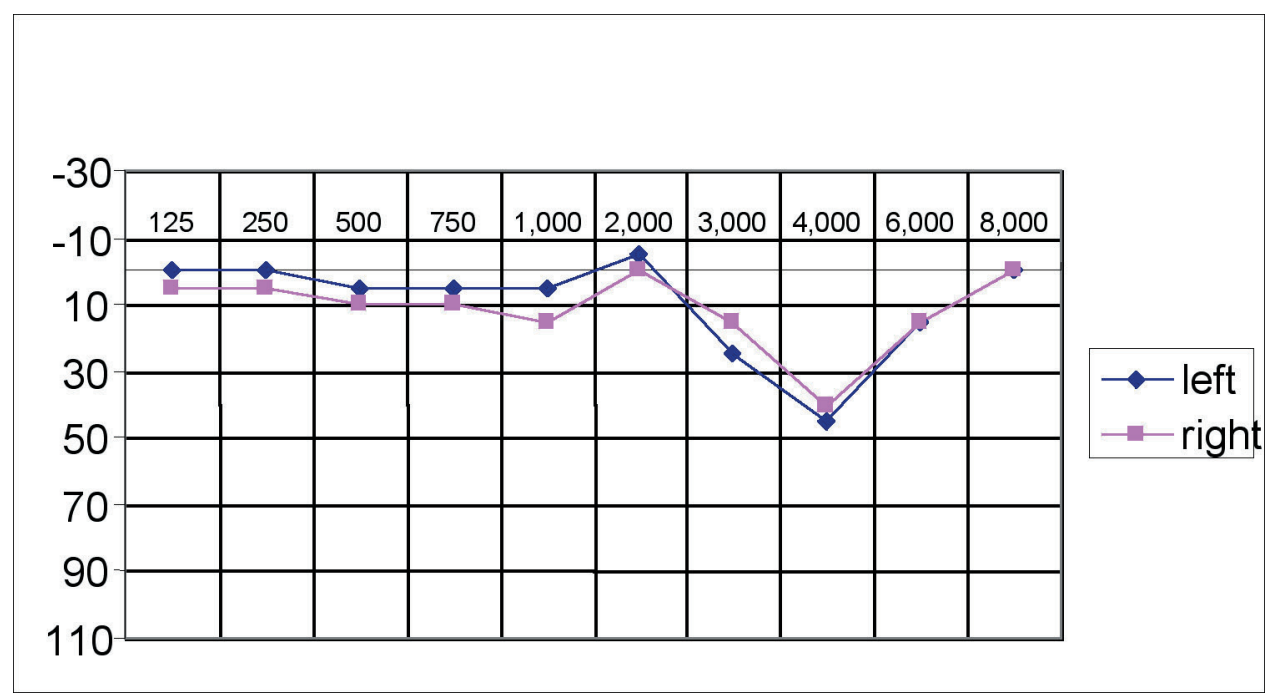


Thirty one per cent of respondents reported experiencing difficulty in hearing when in a noisy room in the work environment. Thirteen per cent reported that they experienced difficulty in understanding when they used the phone at work. Six per cent said they experienced difficulty in understanding when talking to someone in the room where they work. Four per cent said that when they were in a meeting with a small group of people, around a table in a fairly quiet room, they experienced difficulty in understanding. Three per cent reported that if they had to take notes by dictation in a fairly quiet room, they experienced difficulty in understanding.

Pure tone hearing impairment at individual frequencies was analysed, (Table 3). At 3,4 and $6 \mathrm{kHz}$, the prevalence of hearing loss was $24 \%, 25 \%$ and $34 \%$ respectively. These are the frequencies sensitive to noise damage at an early stage and results confirmed that they were affected. At $8 \mathrm{kHz}$ the prevalence of hearing impairment was 38\%. This frequency is most sensitive to age associated hearing loss (AAHL). Noise induced hearing loss affects the frequencies of 3,4 and $6 \mathrm{kHz}$ without impacting on the hearing threshold level of the other frequencies. Comparative analysis was made between the ears. At $3 \mathrm{kHz}$, a greater proportion $(15 \%)$ had hearing impairment in both ears, followed by those who had impairment only in the right ear $(7 \%)$ and then the left $(3 \%)$. At $4 \mathrm{kHz}$, the picture was similar with a greater proportion $(10 \%)$ having bilateral loss, followed by those who had loss only in the left ear (8\%) and then the right (7\%). At 6 $\mathrm{kHz}, 17 \%$ had bilateral loss, followed by loss only in the right ear (10\%) and left ear (7\%). At $8 \mathrm{kHz}, 18 \%$ had bilateral impairment, $12 \%$ had impairment only in right ear and $8 \%$ left ear. Seven of two hundred forty nine $(3 \%)$ of respondents had self awareness of hearing impairment, 20 of $249(8 \%)$ reported that family members had noticed a problem with their hearing and 77 of $249(31 \%)$ reported difficulty in understanding speech in noisy environments. Fifty five of two hundred and forty nine $(22 \%)$ usually had a need to turn up television volume, while $19 \%$ frequently asked people to repeat sentences. One hundred and twenty five of two hundred and forty nine $(50 \%)$ reported that their hearing had reduced compared to how it was 10 years previously, while $45 \%$ reported no change. There was no significant increase in the occurrence of NIHL attributable to the division of residence near the airport. As for income level, the salaries were quite varied in range and no significantassociation could befound betweenincome category and NIHL. Analysis at individual noise sensitive frequencies of 3,4 and $6 \mathrm{kHz}$ showed some interesting patterns. Ground crew had significantly poorer mean hearing threshold level at 3, 4 and 6 $\mathrm{kHz}$ than air crew $(\mathrm{p}=0.015)$. Of the ground crew with NIHL, 50\% worked at the airside ramp and $29 \%$ at apron. Eighty two per cent of respondents were members of trade union. Analysis of mean hearing threshold level at high frequencies $(3,4$ and $6 \mathrm{kHz})$ showed that trade union members had significantly better hearing $(\mathrm{p}=0.021)$.

The duration of exposure to noise was of interest as a risk factor for NIHL. Age category and prevalence of noise induced hearing loss was also of interest. Table 4 shows the comparison between duration of exposures for the NIHL group within the work place. Table 4 also shows the distribution of NIHL at the different age categories.

Table 3

Percent distribution by number of affected ears $(n=249)$

\begin{tabular}{llllll}
\hline & Normal & $\begin{array}{l}\text { Hearing loss } \\
\text { in right ear }\end{array}$ & $\begin{array}{l}\text { Hearing loss } \\
\text { in left ear }\end{array}$ & $\begin{array}{l}\text { Bilateral } \\
\text { hearing loss }\end{array}$ & Total \\
\hline $1 \mathrm{kHz}$ & 34.5 & 18.5 & 10 & 36.9 & 100 \\
$2 \mathrm{kHz}$ & 77.5 & 10 & 4.8 & 7.6 & 100 \\
$3 \mathrm{kHz}$ & 75.9 & 6.8 & 2.8 & 14.5 & 100 \\
$4 \mathrm{kHz}$ & 74.7 & 7.2 & 8 & 10 & 100 \\
$6 \mathrm{kHz}$ & 65.9 & 10 & 7.2 & 16.9 & 100 \\
$8 \mathrm{kHz}$ & 61.8 & 11.6 & 8.4 & 18.1 & 100 \\
\hline
\end{tabular}


Table 4

Distribution of NIHL by duration of noise exposure and by age $(n=249)$

\begin{tabular}{|c|c|c|c|}
\hline \multicolumn{4}{|c|}{ Distribution by duration of noise exposure } \\
\hline Duration (years) & All respondents & NIHL & Prevalence \\
\hline $0-4$ & 56 & 12 & 21.4 \\
\hline $5-9$ & 80 & 10 & 12.5 \\
\hline $10-14$ & 29 & 3 & 10.3 \\
\hline 15-19 & 37 & 6 & 16.2 \\
\hline $20+$ & 33 & 4 & 12.1 \\
\hline Non response & 14 & 3 & 21.4 \\
\hline
\end{tabular}

Distribution by age of respondent (years)

\begin{tabular}{llll}
$20-29$ & 54 & 7 & 13.0 \\
$30-39$ & 85 & 19 & 22.4 \\
$40-49$ & 75 & 10 & 13.3 \\
$50+$ & 24 & 0 & 0 \\
Non response & 11 & 2 & 18.2 \\
\hline Total & 249 & 38 & 15.3 \\
\hline
\end{tabular}

There was no significant statistical difference between the groups with and those without NIHL at the different categories of duration of exposure to noise. There was also no significant statistical difference between those with and those without NIHL at the different age categories. This was possibly due to the small sample size, and small number of those meeting the stringent requirement for diagnosis of NIHL. An analytical approach looking at the hearing threshold levels at the noise sensitive frequencies between the ears and analysing the mean hearing threshold level against the exposure factors of interest like age and duration of noise exposure was considered the next best. This revealed the early noise induced changes and significant statistical differences were notable.
Specifically a look at the hearing threshold levels at $4 \mathrm{kHz}$, considered the most vulnerable frequency to noise damage demonstrated significant differences as shown for age and duration of exposure (Table 5). Logistic regression analysis was done, based on a deviance value of 20.71 on 3 degrees of freedom; the age of the respondent had a significant impact on hearing loss at $4 \mathrm{kHz}$. Respondents in age categories 30-39 years, $40-49$ years and 50+ years were 3.2, 3.3 and 13.7 times more at risk of developing hearing loss than those in the 20-29 years age group respectively. Hearing loss at 4 $\mathrm{kHz}$ was analysed against duration of exposure using logistic regression technique. The duration of exposure was highly significant [Deviance $=23.74$ on 1 degree of freedom, $\mathrm{p}<0.01$ ].

Table 5

Hearing loss at $4 \mathrm{kHz}$ and age of respondent as well as duration of exposure

\begin{tabular}{|c|c|c|c|c|c|c|}
\hline Variable & Level & $\begin{array}{l}\text { Parameter } \\
\text { Estimate }\end{array}$ & $\begin{array}{l}\text { Standard } \\
\text { Error }\end{array}$ & $\begin{array}{l}95 \% \\
\text { Confidence } \\
\text { Interval }\end{array}$ & P-value & $\begin{array}{l}\text { Relative } \\
\text { risk }\end{array}$ \\
\hline \multirow[t]{4}{*}{ Age (years) } & $20-29$ & Reference & & & & \\
\hline & 30-39 & 1.17 & 0.53 & $1.17 \pm 1.04$ & 0.0283 & 3.22 \\
\hline & $40-49$ & 1.20 & 0.54 & $1.20 \pm 1.06$ & 0.0259 & 3.32 \\
\hline & $50+$ & 2.62 & 0.63 & $2.62 \pm 1.23$ & $<0.001$ & 13.72 \\
\hline \multicolumn{7}{|c|}{ Hearing loss at $4 \mathrm{kHz}$ and duration of exposure } \\
\hline \multirow{2}{*}{$\begin{array}{l}\text { Duration of } \\
\text { exposure (years) }\end{array}$} & Less than 10 & Reference & & & & \\
\hline & At least 10 & 1.52 & 0.32 & $1.52 \pm 0.63$ & $<0.01$ & $>10$ \\
\hline
\end{tabular}




\section{DISCUSSION}

Population screening for hearing loss is an essential component of healthcare provision and an integral part of health promotion. Hearing loss is one of the most important occupational diseases worldwide and which in some regions account for the largest occupational injury compensation claims. Many of the pioneering studies assessing hearing loss in aviation have been conducted in military setting, perhaps due to historical origins of aviation medicine and aviation science. Such studies have previously not been done in our region. The use of audiometry as a tool for population screening and risk profiling has now been well established. In Kenya, the study by Aduda (13) on hearing loss in children in Kisumu utilised audiometry with useful results hence reinforcing the feasibility of employing this method in public health setting in this region. In this study at JKIA, the socio demographic characteristics of the workers were investigated. The female workers were outnumbered by their male counterparts at 30\% and $70 \%$ respectively. This was a reflection generally of the sex distribution in most workplaces in Kenya where women representation still lags behind that of the male counterparts and was therefore not unusual. The age range for the respondents was 22 to 62 years with mean 37 years; hence age categories of workers represented at JKIA show a relatively young workforce with people in their most active phase in life. The level of education of the respondents revealed a relatively well educated group with $95 \%$ boasting secondary schooleducation and above. This is pertinent information that should be taken into account when designing intervention measures and determining effective communication techniques to be applied. In terms of salaries, analysis showed that most of the respondents were in the low to medium income category though the variation was wide. The duration of exposure of the workers to excessive noise at the airport was also quite varied ranging from one to forty years with a mean of 10.7 years. Noise damage is dependent on the loudness of noise exposure and the duration.

Worldwide NIHL is a common problem with about 600 million people working in potentially hazardous noisy places (14). It is estimated that up to $20 \%$ have some degree of NIHL. The damage is dose dependent with more damage from noisier environments and long term exposure periods. In USA NIHL is the commonest cause of occupational compensation claims and one of the commonest causes of occupational hazard related litigation (15). Worldwide, $16 \%$ of the disabling hearing loss in adults is attributed to occupational noise, ranging from $7 \%$ to $21 \%$ in the various sub regions with the effects of the exposure to occupational noise being larger for males than females in all sub regions and higher in the developing regions (16). The impact of excessive noise exposure in aviation workers have long been established as demonstrated by the results of the Karachi study (17). In this study, villagers residing near the airport were compared with airport workers in terms of their hearing threshold levels and noise exposure. A significant difference in hearing threshold level of $30 \mathrm{~dB}$ between noise exposed and non-exposed was noted ( $\mathrm{p}$-value < 0.5) (17). The overral prevalence rate of $15.3 \%$ observed at JKIA was lower than that found in helicopter pilots $(32.4 \%)$ and mechanics (47.6\%) in Thailand (18). Whereas our study used commercial aviation workers, the Thailand study involved military officers. The airport work environment was the same, but pre-existing exposure to noise from use of firearms and explosives could have differed and this must be noted. The prevalence rate for NIHL at JKIA was lower than that found in airport workers in Taiwan $(41.9 \%)$ as reported by Ribeiroetal (19). With respect to gender, therehas been a question as to whether there is a sex predisposition. The results of this study documented that males have higher rates of hearing loss than females in a ratio of $4: 3$. This pattern has been noted in several other studies reviewed suggesting that males could be more vulnerable to noise. However the difference was not statistically significant in our study.

Sixty four per cent of the respondents reside in Embakasi Division, close to the airport. Among the NIHL group, $68 \%$ of were Embakasi residents. The fact that majority of workers reside close to their workplace could be related to income levels, convenience, cost of housing, cost of transport and security concerns. Place of residence in proximity to the airport did not have any significant impact on occurrence of NIHL. There was no significant increase in the occurrence of NIHL attributable to the division of residencenear the airport. The hearing loss was attributed to occupational noise exposure at the workplace irrespective of the location of residence. Different work locations at the airport were affected at different rates, and engineers appeared to be the worst affected followed by cargo and freight handlers and then the air crew. Engineers were involved most of the time in the servicing and repair work of the aircrafts and conducted engine runs periodically leading to prolonged exposure to excessive noise. Many of them were assigned duties as line maintenance staff whose work station is largely based at the ramp and aprons. Other engineers and technicians were based at the hangars and workshops. Cargo and freight handlers were also exposed to excessive aircraft noise at the cargo ramp. In addition they were exposed to noise emanating from ground equipment like tractors, trucks, conveyor belts and trolleys which they use constantly as they handle the cargo. The cargo terminal and airside ramp had previously been shown to have excessive noise levels (3). The impact of preventive measures in place is a subject 
for further investigation but the finding that the noisiest areas still have the highest prevalence rates for NIHL rouses the debate on preventive approaches to occupational noise safety at this workplace. Is it possible that not enough is being done and could it be that the approach is ineffective? Elsewhere in the world it has been shown that even the most unlikely areas in aviation practice may be affected by noise damage. Gerostergiou et al (20) in Greece looked at modelers using a one-engine Cessna and ultra light aircrafts in an aviation club and found prevalence of NIHL of $30 \%$. Workers in other transport sectors are also affected by noise induced hearing loss. This has been documented by Barbosa and Cardoso (21) who found significant NIHL among workers exposed to road traffic noise in Sao Paulo Brazil at a prevalence of $28.5 \%$. An industry-wide approach to prevention strategies is therefore called for so as to maximise on safety for workers.

Thirty one per cent of respondents reported experiencing difficulty in hearing when in a noisy room in the work environment. Others reported experiencing difficulty in understanding when using a phone at work or when in a meeting in a fairly quiet room, suggesting that there was a significant impact on the work process efficiency. In a work environment where safety is a key concern, this finding carries considerable interest, as workers must be able to hear and discriminate warning sounds, alarms and other audible signals clearly in order to reduce accidents. As for income level, the salaries were quite varied in range and no significant association could be found between income category and NIHL. Whereas the difference in the NIHL rates between the ground and air crew was not statistically significant, further analysis at individual noise sensitive frequencies of 3, 4 and $6 \mathrm{kHz}$ showed some interesting patterns. These are the frequencies that are most sensitive to noise damage at an early stage. Ground crew had significantly poorer mean hearing threshold level at 3,4 and $6 \mathrm{kHz}$ than air crew $(\mathrm{p}=0.015)$. Of the ground crew with NIHL, 50\% worked at the airside ramp and $29 \%$ at apron. Ramp is arguably the noisiest section of the airport due to aircraft engines and ground equipment. Eighty two per cent of respondents were members of trade union. Analysis of mean hearing threshold level at high frequencies $(3,4$ and $6 \mathrm{kHz})$ showed that trade union members had significantly better hearing $(p=0.021)$. The reasons for this could not be demonstrated by the design of this study. However trade unions in this work place are active in safety issues and educate their members on their rights and obligations.

At the noise sensitive frequencies of 3,4 and 6 $\mathrm{kHz}$, the prevalence of hearing loss was $24 \%, 25 \%$ and $34 \%$ respectively. Noise induced hearing loss affects these high frequencies at the early stages of damage without impacting on the hearing threshold level of the other frequencies to any appreciable level. Comparison of hearing impairment between the left and right ears did not reveal significant differences. Hearing impairment at $8 \mathrm{kHz}$ is most sensitive to age associated hearing loss (AAHL). NIHL was distinguished from AAHL which is impairment solely attributable to aging process and affects mainly frequency at $8 \mathrm{kHz}$. This was distinguishable on the audiogram as a notch at $4 \mathrm{kHz}$ for NIHL as opposed to a dip to the right at $8 \mathrm{kHz}$ for AAHL. The apparently significant hearing loss recorded for the lower pure tone frequencies of $0.125 \mathrm{kHz}, 0.25 \mathrm{kHz}, 0.5 \mathrm{kHz}, 0.75$ $\mathrm{kHz}$ and $1 \mathrm{kHz}$ could be due to the masking effect of background noise during audiometry rather than real. Background noise estimates were not recorded at the time.

These results show a positive correlation between advancing age and NIHL. There is a positive and independent correlation between duration of exposure to noise and NIHL. The average degree of hearing loss at $4 \mathrm{kHz}$ was significantly higher for workers who had been exposed for 10 years and above as compared to those who had been exposed for less than 10 years. This finding is in keeping with those in most similar studies elsewhere. As for age, it was notable that the relative risk of hearing loss at $4 \mathrm{kHz}$ was about three times more for those aged 30 to 49 years as compared to 20 to 29 year olds. The relative risk for the category of 50 years and above was 14 times higher than the 20-29 years group. It is generally accepted that a lifetime of exposure to noise is likely to have negative effects on the hearing, but the interaction between noise-induced hearing loss (NIHL) and age-related hearing loss is difficult to determine. The most commonly accepted assumption is an accumulation of effects of noise and ageing on the hearing. NIHLbefore old age may reduce the effects of ageing at noise-associated frequencies, but accelerate the deterioration of hearing in adjacent frequencies. This line of argument has been investigated by other workers and evidence supporting it is increasing. The findings of Rosenhall from the longitudinal and crosssectional gerontological and geriatric population study of 70-year-olds in Gothenburg, Sweden are supportive of this argument (22). Further analysis of the hearing threshold level of the JKIA workers with occupational noise exposure will be necessary to determine subtle associations and trends.

In conclusion, NIHL does occur in the noise polluted areas at JKIA with the prevalence rate at $15.3 \%$. Ground crews were more affected than air crew. The older age categories were more vulnerable. The findings document some of the socio demographic attributes of affected workers. Results imply that there is a need for action to ensure prevention of this medical condition. Elsewhere it has been demonstrated that NIHL is $100 \%$ preventable. Male sex, working as a 
ground crew and older age were associated with a poorer mean HTL at the noise sensitive frequencies and an increased occurrence of NIHL. Ground crew were presumed to be more exposed to excessive noise than air crew since most of the newer aircrafts were less noisy. Some of the ground equipments remain excessively noisy, especially the tractors.

It is recommended that periodic audiometric assessment of workers especially targeting older workers be done. It is further recommended that a comprehensive NIHL prevention programme be put in place at JKIA.

\section{ACKNOWLEDGEMENTS}

To all the respondents from Jomo Kenyatta International Airport who volunteered to participate in the research work. Appreciation goes to the management of Kenya Airports Authority and Kenya Airways for their support. We also wish to thank the Kenyatta University administration for facilitating the research. This work formed part of the requirements for the award of the degree of Master in Public Health of Kenyatta University to the principal author.

\section{REFERENCES}

1. Ballenger, J.J. Editor. Diseases of the nose, throat, ear, head, and neck, $13^{\text {th }}$ ed. Leah \& Febiger. Philadelphia. 1985.

2. Fernandes S. J. C., Carvalho A. P. O., Gallas M., Vaz P. and Matos P. A. Noise levels in dental schools. Eur. J. Dent. Educ. 2006; 10: 32-37.

3. Mutinda, D. Kenya Airways Noise Level Survey Report. Kenya Airways, Nairobi. 2004.

4. Kamau W. M. Kenya Airports Authority Initial Environmental Audit Report, Jomo Kenyatta International Airport. NEMA, Nairobi. 2006.

5. Muriuki A. W. Kenya Airways Occupational Hygiene Survey; Noise and Air Quality Assessment Report. Kenya Airways, Nairobi. 2007.

6. GoK. Legal Notice No. 24, The factories and other places of workAct [Cap.514]. Kenya Gazette Supplement No. 22. 2005.

7. Rabinowitz, P.M. Noise induced hearing loss. Am. Fam. Physician. 2000; 61: 2749-2756.

8. Carhart, R. and Jerger, J. Preferred method for clinical determination of pure tone thresholds. J. Speech Hear. Disord.1959; 24: 330.
9. $\quad$ Fisher P., Blackwell S., and Belle V. Sample size and Power. Oxford University Press. Oxford. 1998.

10. Nassiuma, D. K. Survey Sampling Theory and Methods. Nairobi University Press. Nairobi. pp134, 2000.

11. Amanda, S. N. Kieszak, S. M., Holmes, A. E., et al. Estimated prevalence of noise-induced hearing threshold shifts among children 6 to 19 years of age: The Third National Health and Nutrition Examination Survey, 1988-1994, United States. Pediatrics;2001;108: 40-43.

12. Yetter, C. J. How to read an audiogram.www.wou. edu/wroc. 2007.

13. Aduda, D.S.O. Epidemiology of hearing impairment and impact on socio-cognitive performance on school going children in Kisumu District, Kenya: Implications for public health action. MPHE Thesis, Kenyatta University. 2005.

14. Irwin, J. What are the causes, prevention and treatment of hearing loss in the ageing worker? Occup. Med. 2000; 50: 492-495.

15. Daniell, W.E., Swan, S.S., McDaniel, M.M., et al. Noise exposure and hearing loss prevention programmes after 20 years of regulations in the United States. Occup. Environ. Med. 2006; 63: 343-351.

16. Nelson, D. I., Nelson R.Y., Concha-Barrientos M. and Fingerhut $\mathrm{M}$. The global burden of occupational noise-induced hearing loss. Amer. J. Indust. Med.2006; 48: 446-458.

17. Siddiqui I. A., and Siddiqui R. A. The effects of excessive noise exposure on the hearing thresholds of aviation workers in Karachi. Pak. J. Med. Sci. 2008; 24: 525-530.

18. Jaruchinda, P., Thongdeetae, T., Panichkul S. and Hanchumpol, P. Prevalence and an analysis of noiseinduced hearing loss in army helicopter pilots and aircraft mechanics. J. Med. Assoc. Thai. 2005; 88 Suppl 3:S232-S239.

19. Ribeiro, A.M. and Camara, V.M. Hearing loss by continuous exposure to high sound pressure among maintenance workers at a Brazilian Air Force helicopters unity. Cad. Saude Publica. 2006; 22: 12171224.

20. Gerostergiou, E. Tsitiridis I. Batzakakis, D. et al. Sensorineural hearing loss of noise in members of aviation club of Larissa (Greece). Hippokratia. 2008; 12(Suppl 1): 59-63.

21. Barbosa, A.S.M. and Cardoso M.R.A. Hearing loss among workers exposed to road traffic noise in the city of São Paulo in Brazil. Auris Nasus Larynx. 2005; 32: $17-21$

22. Rosenhall, U. The influence of ageing on noiseinduced hearing loss. Noise Health. 2003; 5: 47-53. 